This article examines two approaches to analysing qualitative data, namely the template approach and the interpretative phenomenological approach. Each has been used in an evolving research project, which explores the reasons that women give for engaging in artistic occupation as a means of coping with illness. A discussion of the strengths and limitations encountered in each analytical method is provided. The key objectives of this article are to explore some of the strengths and limitations of each of these two analytical methods and to illustrate how the choice of analytical strategy may affect research findings. This may be helpful for students and therapists who are considering carrying out a qualitative research project.

\title{
Exploring the Meanings of Artistic Occupation for Women Living with Chronic Illness: a Comparison of Template and Interpretative Phenomenological Approaches to Analysis
}

\author{
Frances Reynolds
}

\section{Introduction}

There is increasing recognition that qualitative research does not consist of a 'unified set of techniques or philosophies' (Mason 1996, p3). Holliday (2002, p21) argued that 'qualitative research has ... grown from both interminglings and divisions, resulting in a complex family of inter-related methods and approaches'. Researchers who are setting out on a qualitative research study, therefore, inevitably face choices about the epistemological approach or tradition that they will follow (Creswell 1998).

A recent edition of the American Journal of Occupational Therapy provided candid personal accounts of the challenges and dilemmas that some researchers have faced when carrying out qualitative data analysis (for example, Bailey and Jackson 2003, Dickie 2003). Dickie (2003, p51) made a plea for qualitative researchers 'to tell the reader about the thinking that went on during the process of transforming data into a coherent description and sound interpretations' The present article adds to this exploration and debate. One objective is to show how a particular analytical strategy affects, to some extent, the research findings because it brings some aspects of the data into focus and relegates other aspects to the background. This discussion may be particularly helpful for researchers who are setting out on their first qualitative study and making decisions about the most appropriate qualitative paradigm.
This article is based on my experiences of using the template and interpretative phenomenological approaches to qualitative data analysis and explores some of the strengths and limitations that were encountered with each analytical approach. Both approaches were used within the context of a particular evolving research project into the meanings of artistic occupation for women living with chronic illness.

Template analysis essentially approaches qualitative data analysis with a 'start-list' of themes or categories that are anticipated from the outset; for example, those based on relevant theory. It is an approach to analysis that is fairly structured and, for that reason, it may appeal particularly to novice qualitative researchers. Interpretative

phenomenological analysis (IPA), as the name suggests, sets out to be responsive to each participant's own voice. Smith et al (1997) argued that the aim of this approach was to 'explore the participant's view of the world and to adopt, as far as possible, an "insider's perspective"" (p69)

Each approach is fundamentally associated with a particular epistemology or theory of knowledge. The template approach better suits a 'realist' philosophy, where the researcher assumes that the issues and strategies that participants describe are fairly durable and genuinely reflective of their psychological and social worlds rather than constructed in the moment-by-moment interview (Crabtree and Miller 1992). The interpretative style of analysis suits a more 'constructionist' philosophy, with the researcher approaching interview data from the perspective 
that it is constructed by both interviewee and interviewer together and accepting that the researchers interpretation is but one legitimate way of understanding the material collected (Dickie 2003).

The article discusses both qualitative approaches to analysis, outlining:

- The background to the research project

- A template approach to qualitative data analysis

- The strengths and limitations of the template approach that emerged in the study

- Interpretative phenomenological analysis (IPA)

- The strengths and limitations of IPA that emerged in the study.

\section{Background to the research project}

This article is based on my experience of carrying out two studies that explored the meanings of artistic occupations (in particular, textile arts) for women who were living with long-term health problems (Reynolds 1997, Reynolds and Prior 2003). Inquiry into the meanings of occupation for people in the community who are coping with illness and life transitions is a growing area of occupational therapy research (for example, Christiansen et al 1999, Jonsson et al 2001, Lyons et al 2002). A better understanding of the phenomenology of occupation may help to inform professional practice.

Following ethical permissions, the initial study was based on a set of written narratives; the second study drew almost entirely upon in-depth, transcribed interviews. As the population of women with long-term health problems who enjoy artistic occupations, in particular textile arts, is unknown and hidden, convenience samples were quite acceptable in each case. Following precedents such as Mansfield et al (1992), invitations to participate in each study were placed in community settings and in a textile arts magazine.

In the first study, volunteers living with long-term health problems were invited to write about their experiences. They were asked to describe the process through which they had discovered a personal interest in the textile arts, identifying the sources of satisfaction in their artwork and commenting on whether and how art making helped them to cope with their illness. Written narratives have been underused by qualitative researchers, although a few have argued that they provide legitimate and illuminating data (Robinson 1990, Mason 1996, Kralik et al 2000). Thirty-five women with physical health problems contributed to the first study by writing extensive accounts of their personal experiences of engaging in art as a means of coping with ill-health (Reynolds 1997). Thirty women volunteered to be interviewed for the second study about similar issues.

To provide the reader with an example of the qualitative data for which a suitable analytical procedure was required, the following extract, written by a woman aged about 50 years, is offered:
I have had problems with my back for many years but in 1984 the problem became so severe I was hospitalised for a couple of weeks, then spent many weeks confined to the house, and for much of the time confined to my chair. Having been a fit and active person I found this very difficult to cope with and needlework was my salvation ... this not only took my mind off the pain but gave me a great deal of pleasure. Even after I recovered enough to resume some of my former activities, I continued to stitch whenever I had the time ... There have been times when I have been very low indeed and I firmly believe that textile artwork has been of inestimable benefit. It helps one relax, and when others appreciate it, it helps to restore one's self-esteem. It is not only a hobby but a means of self-expression.

Intuitively, this extract seems to suggest that artwork has an abundance of personal meanings for this respondent. Yet as a qualitative researcher, I was aware that there were several distinct analytical methods to choose from if I was to succeed in uncovering and interpreting such meanings in a robust and systematic way. In the analysis of personal narratives, there is inevitably a further decision to be made. This concerns whether the words of the respondent should be interpreted as conveying an enduring personal reality, or whether they are better regarded as constructed in the moment-by-moment occasion (of writing or being interviewed) to create a particular identity or desired image for the researcher (Crossley 2000).

If an enduring personal reality is inferred, there is a further dilemma about whether to regard the text as an authentic representation of the person's subjective state of mind or as objectively factual. For example, in the extract above, it is possible that the description of being a 'fit and active person' was indeed accurate. Alternatively, the statement may reflect the person's memory of that time, which possibly magnified the contrast between her current and past physical health.

Personal biography (including academic background and personal values) may influence the researcher's position on this issue. For example, researchers who have been steeped in client-centred values through their education (for example, in occupational therapy) may prefer to regard the participants' accounts as a genuine attempt to convey what they have experienced about their illness and the therapeutic value of art, rather than a performance constructed for the purpose of conveying a desired self-image to the researcher. A researcher with expertise in critical sociology or discourse analysis may take a different approach.

Many qualitative researchers argue that all forms of qualitative data analysis need to provide a credible and transparent method of summarising and interpreting the data (Lincoln and Guba 1985). Some hold that the analysis needs (at least potentially) to be confirmable by others, to reassure the reader that the researcher has not simply projected his or her own fantasies onto the participants' own meanings (Silverman [2000], for example, discussed this issue). On the other hand, those who accept that all 
qualitative data analysis is inevitably a matter of interpretation caution against the notion that one researcher's analysis can easily be validated and look instead to criteria such as the usefulness, plausibility and acceptability of the analysis to informants (for example, Reissman 1993).

My personal biography probably influenced the form of analysis carried out in the first study, coupled with the nature of the written data which could not be probed or checked with the respondents. I had been exposed mainly to cognitive psychology and quantitative methods in my education as a psychologist and, in 1993-94, at the start of the project, I was fairly new to qualitative research. For these reasons, I sought an analytical method that promised to be straightforward and confirmable. The template approach did not quite live up to this promise and the difficulties that arose are examined below.

\section{A template approach to data analysis}

Miles and Huberman (1994) recommended the template approach to data analysis. However, Dickie (2003) pointed out that these authors are two of the most 'quantitatively orientated' of qualitative researchers. A template provides an initial framework of categories, otherwise known as a start-list, which can be applied to the data collected.

The template can be derived from a number of sources, such as previous theory or research evidence. It thereby enables the researcher to search for theoretically relevant units of meaning within the text (Crabtree and Miller 1992). The template can also be derived from the specific questions within the interview guide. The a priori categories (that is, the categories or themes decided in advance of data collection) help to provide structure to the process of data analysis, assisting the researcher to segment the text meaningfully and manageably.

With a template, it is possible to determine how frequently the various anticipated themes occur in respondents' accounts and thereby make certain inferences about common experiences within the sample. Ultimately, the template analysis can also highlight unexpected themes. These are the issues in the narratives that remain uncoded after the template has been applied.

For a researcher relatively new to qualitative analysis, I thought that this approach would be fairly straightforward. My theoretical approach to understanding the illness experience at that time had been influenced by the cognitive-behavioural perspective of Moos and Schaefer (1984). These authors, on the basis of their research, argued that chronic illness presents people with a number of general challenges (or 'tasks'), if they are to cope successfully. These tasks or challenges are:

1. To preserve a satisfactory self-image and sense of achievement or competence

2. To retain a psychological equilibrium (for example, maintaining hope and humour and controlling anxiety)
3. To maintain positive relationships with family and friends

4. To prepare for an uncertain future.

By applying this theoretically derived template of categories to participants' accounts, I hoped to show that artistic occupation helped them to master all of these challenges.

\section{Reflections on some strengths and limitations of the template approach}

\section{Strengths}

A professed advantage of the template approach to analysis is that the findings can be readily related to existing theory. This proved to be the case in this study. For example, it was clear that artistic occupation helped many of the respondents to address the challenges of chronic illness (as formulated by Moos and Schaefer 1984) because a large proportion of the respondents described their artwork as restoring emotional equilibrium and self-esteem (Reynolds 1997). Some made textile products as welcomed gifts to reciprocate care within their families, helping to maintain social relationships. It was interesting to note that the women whose illness had enforced recent early retirement from work, with consequent loss of role, status and financial security, were particularly likely to perceive textile artwork as restoring self-esteem and an 'able' identity.

Furthermore, having applied the template to the data, other issues emerged that went beyond the start-list of categories. For example, the Moos and Schaefer (1984) model does not explicitly acknowledge the financial insecurity that chronic illness often brings about. Yet some of the women emphasised the economic misery of illness and described how they sold their textile artwork to make a small income. By examining the aspects of the narratives that had not been addressed by the template, the list of coping tasks in illness could be extended and further insights were gathered about the role of creative art making in living positively with long-term health problems.

\section{Limitations}

Nevertheless, although it offered a practical approach to data analysis, certain disadvantages or limitations of the template approach soon became apparent. Most importantly, in this particular study, the selected template provided broad rather than fine-grained categories. For example, 'retaining psychological equilibrium' seemed to cover many specific needs, ranging from dealing with fearful thoughts and alleviating feelings of helplessness to relaxing and having fun. These specific responses to the creative process were rather lost if only the large categories of the Moos and Schaefer (1984) scheme were considered. Furthermore, doubts about the most appropriate categorisation of the data arose in the analysis of many sections of the text. For example, the following quotation could be placed in more than one of the Moos and Schaefer (1984) categories: 
The common thread (if you'll excuse my pun) is the sense of achievement ... Creating something that would not exist if it wasn't for me is immensely satisfying. It also gives a sense of control that is very often lacking in a disabled/ill person.

This extract was initially placed in the first category as 'preserving a satisfactory self-image and sense of achievement or competence' (Reynolds 1997), but an alternative classification could be justified such as 'retaining/restoring emotional equilibrium'. Furthermore, the respondent mentions creativity, control and possibly a need to be socially visible (issues that the Moos and Schaefer [1984] classification might or might not subsume under the broad task of maintaining 'psychological equilibrium'). A finer-grained analysis might be desirable to increase sensitivity to the many facets of each respondent's experience of artistic occupation.

It also became evident that this particular template, if used exclusively, would limit the researcher's interpretation of the data. The Moos and Schaefer (1984) model, for example, is highly psychological, indeed cognitive, in its focus. Because the social and cultural dimensions of the illness experience are more or less absent from the template, they risk being overlooked in the narratives. Once immersed in the written narratives, I found myself becoming increasingly interested in the women's descriptions of the process whereby they had 'discovered' textile arts as a meaningful occupation in illness and in the stories that they told about how role models and family values helped them to cope with adversity. An additional, complementary approach to data analysis was required.

A further limitation of the template approach emerged, namely that it tended to fragment the data, destroying its coherent phenomenological quality. Crabtree and Miller (1992), however, argued that this could be overcome by adopting a subsequent interpretative phase in the analysis in which the units or categories were connected together to form a meaningful theory.

The template approach was found to have another disadvantage in encouraging a focus on the content rather than on the structure of the narrative. Yet the structural and linguistic aspects of the narratives seemed to provide further insights into the lived experience of disability and creativity. The women's choice of words and phrases (for example, sometimes describing themselves with highly self-deprecating words such as 'useless') conveyed additional insights into the experience of illness and its potentially devastating effects on identity. It may be argued that any analysis can justifiably be adapted and extended beyond the confines of the initial method. After all, all codes and categories are 'tools to think with' (Coffey and Atkinson 1996, p32) and are not rules to obey unquestioningly. Nevertheless, once I saw the value of a more flexible and responsive approach to the data analysis, I began to doubt the need to set out equipped with an a priori template in the first place.

\section{A phenomenological approach to analysis}

A different analytical approach was attempted in the follow-up study, to infer meanings from the in-depth interviews with 30 women coping with long-term health problems. The interviews explored the women's views on the contribution of artistic occupation to maintaining identity and wellbeing in chronic illness. They explored the women's experience of illness and disability, the process whereby their interest in textile arts had developed, and the part that artwork had played in promoting wellbeing, positive identity and coping with change (Reynolds and Prior 2003). A different analytical strategy was adopted, partly because a template approach does not seem to lend itself to segmenting large amounts of qualitative data (gained from interviews as opposed to written narratives) and partly because a fresh approach to qualitative research (Smith et al 1997, 1999) had gained growing acceptance, at least within the health psychology literature.

Studies of people's experiences of health and illness based on interpretative phenomenological analysis (IPA) include Flowers et al (1997), Golsworthy and Coyle (1999), Smith (1996) and Thompson et al (2002). This analytical approach concerns itself with the nuances of participants' own described experiences. Smith et al (1997, p68) argued that 'a central premise of the method is allowing participants to tell their own story, in their own words, about the topic under investigation'. It is an approach that also accepts that each researcher brings particular concepts to the process of analysis. Hence, Smith et al (1997, p68) acknowledged that 'the resultant analytic account can therefore be said to be the joint product of the reflection by both participant and researcher'.

Based on the textbook guidelines for IPA (Smith et al 1997, 1999) three long and rich interview transcripts were initially selected, provided by women living with different physical illnesses. The transcripts were initially read many times to infer recurrent themes in the narrative accounts. Brief descriptive codes were annotated on each transcript and, after much immersion in the data, these were grouped into broader interpretative themes. The themes were checked and added to during the subsequent analysis of the remaining transcripts. Particular attention was given to the themes that the interviewees had validated at the time of the interview, when their views had been summarised and reflected back by the interviewer. My colleague Sarah Prior (an occupational therapist) carried out an independent coding of the initial set of transcripts. Through discussion, we resolved decisions about the higher order interpretative themes.

\section{Reflection on the strengths and limitations of the interpretative phenomenological approach}

\section{Strengths}

What did IPA offer this particular research? It encouraged an 
openness to the data that (with hindsight) had been somewhat constrained previously when applying an a priori template. For example, sensitivity to the structure as well as to the thematic content of the narratives was possible. It was observed, for instance, that the women responded to the initial grand-tour question in the interview (which asked them to describe themselves and the events in their lives that had been important to them) by focusing on life since the onset of illness. Description of the earlier 'healthy' phase of life was brief or non-existent. Many significant personal events were omitted, such as job, marriage and the birth of children (although references to these came later in the interviews). The following opening statements in the interviews illustrate this pattern (pseudonyms are used):

Bridget (early 60s; has breast cancer and other health problems): I've had arthritis since I was 26, then I think the next big thing was kidney stones, I think it was in that order [pause] breast cancer, then as a result of long-term taking of steroids, and anti-inflammatories, I had a little gastric, or duodenal ulcer, and then the latest thing, about 18 months ago, diagnosed with osteoporosis, which has been far worse than all the others put together ... I don't get out of the house now, unless anybody comes right to the door, picks me up, helps me in with my bag, into the car, carries my bags, and then comes back and takes me in again. But that's OK, I'm one of those people, if I can't do one thing, then I'll carry on and do something else.

Sue (late 40s; has multiple sclerosis): Um [pause] I'm 48 years old, I've had it [MS], diagnosed since I was about 36 (um) when I was still working, I've got three daughters, (um) one's a nurse, one lives abroad, and one lives locally [pause] er [pause] what else do you want to know [laughs]?

Interviewer: Take your time.

Sue: I worked with social services, and then I retired on medical grounds, because the illness kept recurring ... (um) I'd never sewn, never stitched before, I was an outdoor person, horse-riding, dogs, bringing the children up (um) and then all of a sudden it stopped (um) retirement on medical grounds as I stated. Then my daughters grew up, my job stopped and I was suddenly left with this huge void, and er what do you do? And I've always loved craftwork, always loved to see it, always loved to go to galleries ... and [laughs] I found a craft-book and I tried to do patchwork [laughs]. Absolute disaster! [laughs] ... I thought this is bloody stupid!! [laughs] But I persevered. I started off with patchwork. And I got hooked.

The prioritising of these experiences within the narratives could be interpreted as conveying the message that the onset of illness had formed a dramatic turning point in the women's life and identity. This interpretation is supported by Reissman (1993, p64), who claimed that 'telling about complex and troubling events ... is a selective reconstruction. Individuals exclude experiences that undermine the current identities they wish to claim'.

It was also striking that most of the women, across the entire interview, conveyed an energetic and enthusiastic approach to life. Such broad inferences from the narratives as a whole are not encouraged by the template approach, which seeks to match fragments of text with the available theoretical categories. Yet, from engaging in a more phenomenological approach, I found myself speculating as to whether artwork provided an alternative means of retaining an active and busy lifestyle, thereby preserving aspects of a valued self, even when illness had curtailed other roles. Artistic occupation could therefore be interpreted as maintaining the women's characteristic sense of personal agency:

\section{Sue (describing weekend activities prior to the onset of multiple sclerosis and using a wheelchair): I used to work alternate weekends, but the weekends we weren't working we used to go off and do lots of things, we used to go up to London, and train and bus-hop on these bus tickets that used to cover whole areas, we used to go to St James's Park, Buckingham Palace, ... all the markets ... And we'd pack up sandwiches and we'd put them into ordinary bags, so we could eat the sandwiches and then throw the bags away, and then we just used to go round London, my daughters speak about it even now, it was great, it was great, so we've done lots of things ... there was always lots to do, lots of things, but active things.}

Such hunches about the subjective importance of agency and the continuity of self in illness did not emerge so readily when a template approach was used to segment the data in the earlier study, even though, looking back at the written narratives, there were many signs of these themes. The phenomenological approach also uncovered a recurring theme within the stories that had not been clearly visible using the template approach, namely that most participants described confronting a problematic void once illness had intruded into their careers, family roles and favoured pastimes (Reynolds 2002). Artistic occupation functioned to fill this void and, thereby, offered a means of biographical, or identity, repair.

The phenomenological approach also increased awareness of the spontaneity offered by artwork, which stood in marked contrast to the effortful coping tasks of illness. For example, women who were highly restricted in their everyday activities through mobility problems often referred to enjoying the spontaneity that their artwork offered:

Sue (uses a wheelchair, has MS): Yesterday I painted up some fabric so I'm going to stitch over that with the machine. I'm going to make a book again ... see what I come up with, just playing around ... I quite enjoy just doing that part, just stitching up and down, just colouring in bits of fabric, seeing what I come up with, and if I like it I think yes I could make a bag out of that, or a book, or a quilt, or a wall-hanging [pause] ... that's what I love about it, that's why I think it absorbs me so much because it takes me, what I have in mind, by the time of the end product might be totally different ... [It's] the spontaneity which sees me through the bad times, because as it flows through me, if you know what I mean, there's no restrictions.

The IPA gave rise to a diverse array of themes about the contribution of artistic occupation to health and wellbeing. 
It also permitted exploration of the women's social context. It was interesting to note many shared themes in the narratives, not only from the three women initially selected for detailed analysis but also in the remaining transcripts which were analysed subsequently. Almost all had had professional careers prior to illness, described their husbands as very supportive and were financially solvent; the majority lived in fairly rural, stable communities. This observation raised questions about the social and economic resources that might empower women to take up artistic occupations in middle to later life as a means of coping not only with the symptoms of illness but also with enforced retirement on the basis of ill-health. Clearly, the nature of the volunteer sample precludes generalisation. A further research project could check whether such resources were common in a larger sample of textile artists who regard art as a central means of living positively with adversity.

Many strengths of the phenomenological approach have been described. The detail of the analysis, its flexibility, the positive experience of being able to respond creatively to the narratives, the devotion of attention to respondents' meanings rather than to pre-existing theory and the sensitisation to the linguistic features of the text as well as to the content all helped to heighten understanding of the respondents' frames of reference. Many intriguing clues were inferred about the personal, social, economic and cultural resources of the respondents that enabled them to reconstruct life and identity around artistic occupation.

\section{Limitations}

Nevertheless, within this particular research project, IPA also presented certain challenges or disadvantages, some practical and some theoretical. The analytical process not only was time consuming but also did not clearly reach a definite and convincing end point. This problem seems generally to be glossed over in most research reports that refer to achieving 'category saturation' (a point where no new information is forthcoming from the data collection and analysis). Dickie (2003, p52), however, noted that saturation was a problematic concept and that there was 'always new information to be had ...' She argued that the issue was perhaps better addressed by deciding when 'there is "enough" of the story waiting to be told'. Perhaps it is the case that the multiple strands of meaning within complex qualitative accounts cannot all be unravelled by a single analytical method.

As a further practical problem, the sample size of 30 presented a considerable challenge for the painstaking analysis required by IPA. Whereas funding agencies may be unwilling to accept projects that are based on very small numbers of participants, researchers need to be mindful that, if they propose to interview a sample of this size, a detailed IPA of each transcript will represent an enormous challenge. One solution may be to use this phenomenological approach for an initial 'sensitising' phase of the inquiry only, with perhaps fewer than 10 participants.

Traditional phenomenologists argue that 'bracketing' (the process of becoming aware of, and then setting aside, presumptions and theoretical frames of reference) is vital because we need to gain awareness of our assumptions and values in order to be less influenced by them (Van Manen 1990, pp46-47). Only then can we really expect to gain entry into other people's 'life worlds' (Crabtree and Miller 1992). Yet one might argue that the process of 'bracketing' is enormously difficult, if not conceptually impossible.

It may be considered fortunate that there is greater acceptance among people engaging in IPA that narratives are co-constructed by researcher and participant, and that each researcher may formulate a rather different, yet legitimate, analytical account. Nevertheless, some IPA researchers, such as Thompson et al (2002), have used co-researchers to help validate the analysis. Bailey and Jackson (2003) also discussed the value to a project of having researchers who bring different backgrounds in qualitative research and different sensitising concepts. I found that a second coder was very helpful to IPA, particularly in bringing certain different professional perspectives to the topic whilst offering reassuring support for many of the key themes that I had inferred from the data.

\section{On balance}

On balance, I found that IPA was very useful to deepen my understanding of the variety of formative experiences and influences that enabled some women to live positively with illness through artistic occupation. The two qualitative studies, despite their different approaches to data collection and analysis, uncovered certain shared perspectives on the ways in which creative art making assists people to live positively with chronic illness (such as art as a relaxing experience and as a means of expanding social networks). The template approach was adequate for finding out about certain coping tasks and strategies in illness. However, IPA enabled me to develop a richer understanding about the biographical influences that encourage immersion in artistic occupation during chronic illness and the process of identity reconstruction during chronic illness.

Perhaps most importantly, IPA suggested that art making contributed to the respondents' satisfaction with life as a whole and did not simply function as a means of coping with illness. This wider purpose could not really be identified from the template approach. One respondent explained how her varied creative activities helped her to lead a full life:

Bridget (early 60s; has rheumatoid arthritis, has recovered from breast cancer, has severe osteoporosis, rarely leaves the house because she has severe mobility problems): My quality of life is excellent, absolutely excellent. I could make a very good case for it being bleak, very bleak, but I have chosen to turn it around and in fact it's not bleak at all, it's just absolutely wonderful. I haven't really got the time to do all the wonderful things that I've got planned, all the things I've started, all the projects, all the books, all the things I've listed I might do. I've made it a very, very enjoyable life ... about 90\%, and I read a lot, and I do like to think that I write a little bit, nothing very much in the way of being published, a few poems ... but I read, I write, I sew, I do so many things really, ... The list is endless really. 


\section{Conclusion}

The article has described the evolution of a research project, from an initial exploratory feasibility study based on written narratives and template analysis to a more in-depth interview phase, guided by IPA.

The template approach to analysis had the advantage of facilitating a theoretically driven analysis and it provided a relatively straightforward tool, which may appeal especially to researchers new to qualitative research. However, the quality of analysis was ultimately dependent upon the suitability of the template. The rather large theoretical categories in this study perhaps limited the insights that could be derived.

For the second study, the in-depth analysis of selected transcripts in the first phase of IPA provided a manageable start, and then further themes were added and elaborated with the remaining interview data. This more interpretative approach to analysis encouraged openness to the participants' voices and to fresh perspectives. The narrative structure as well as the thematic content provided clues to the experience of engaging in artwork as a means of living a full life in the context of chronic illness. The textbook accounts of IPA were found to provide a workable set of guidelines to follow and the analytical approach encouraged creative responsiveness to the data, a more holistic understanding of individual experiences of identity reconstruction and a greater sensitivity to participants' linguistic and narrative strategies. However, a second coder was definitely useful to increase awareness of personal assumptions and to demonstrate the credibility and confirmability of the analysis.

A larger set of themes in the narratives was derived by IPA than by the template approach. Nevertheless, neither analytical approach appeared to provide clear guidelines for giving weight to the participants' own interpretations of the data, for conceptualising the mutual effects of researcher and participant on the data collected or for analysing the structure of the narratives.

The ultimate choice of analytical method would appear to depend upon many factors, including the researcher's favoured epistemology (for example, do you favour a 'realist' approach, regarding interviewees as communicating their enduring psychological values and experiences during the interview, or do you favour a 'constructionist' perspective, assuming that participants construct their accounts for a specific purpose?) Furthermore, the type of qualitative approach may also depend upon the type and volume of data collected, the existence of relevant pre-existing theory, the researcher's own research background and, of course, the research question.

This list may imply that only one analytical strategy is likely to be appropriate for a specific project, but some researchers are increasingly arguing that rich qualitative data require the use of multiple methods of analysis (for example, Reissman 1990, Bailey and Jackson 2003). More accounts of researchers' personal experiences of carrying out qualitative methods of analysis, singly or in combination, would be welcome. Such inside information might be helpful for encouraging the wider participation of occupational therapists in research.

\section{Acknowledgements}

The author is grateful to the Arts and Humanities Research Board (UK) for its financial support of the second project described in this article and also wishes to thank Sarah Prior for her contribution to the work reported here.

\section{References}

Bailey D, Jackson J (2003) Qualitative data analysis: challenges and dilemmas related to theory and method. American Joumal of Occupational Therapy, 57(1), 57-65.

Christiansen C, Backman C, Nguyen A (1999) Occupations and wellbeing: a study of personal projects. American Journal of Occupational Therapy, 53, 91-100.

Coffey A, Atkinson P (1996) Making sense of qualitative data: complementary research strategies. London: Sage.

Crabtree BF, Miller WL (1992) Doing qualitative research. London: Sage.

Creswell J (1998) Qualitative inquiry and research design: choosing among five traditions. London: Sage.

Crossley M (2000) Introducing phenomenological psychology: self, trauma and the construction of meaning. Buckingham: Open University Press.

Dickie V (2003) Data analysis in qualitative research: a plea for sharing the magic and the effort. American Joumal of Occupational Therapy, 57(1), 49-56.

Flowers P, Smith J, Sheeran P, Beail N (1997) Health and romance: understanding unprotected sex in relationships between gay men. British Journal of Health Psychology, 2(1), 73-86.

Golsworthy R, Coyle A (1999) Spiritual beliefs and the search for meaning among older adults following partner loss. Mortality, 4(1), 21-40.

Holliday A (2002) Doing and writing qualitative research. London: Sage. Jonsson H, Josephsson S, Kielhofner G (2001) Narratives and experience in an occupational transition: a longitudinal study of the retirement process. American Joumal of Occupational Therapy, 55(4), 424-32.

Kralik D, Koch T, Brady B (2000) Pen pals: correspondence as a method for data generation in qualitative research. Journal of Advanced Nursing, 31(4), 909-17.

Lincoln Y, Guba E (1985) Naturalistic inquiry. Beverly Hills, CA: Sage. Lyons M, Orozovic N, Davis J, Newman J (2002) Doing-being-becoming: occupational experiences of persons with life-threatening illnesses. American Journal of Occupational Therapy, 56(3), 285-95.

Mansfield PK, Theisen SC, Boyer B (1992) Midlife women and menopause: a challenge for the mental health counsellor. Journal of Mental Health Counselling, 14, 73-83.

Mason J (1996) Qualitative researching. London: Sage.

Miles M, Huberman M (1994) Qualitative data analysis. 2nd ed. London: Sage.

Moos RH, Schaefer JA (1984) The crisis of physical illness: an overview and conceptual approach. In: RH Moos, ed. Coping with physical illness, 2: newperspectives. New York: Plenum Medical, 3-25.

Reissman C (1990) Divorce talk: women and men make sense of personal relationships. New Brunswick: Rutgers University Press.

Reissman C (1993) Narrative analysis. Newbury Park, CA: Sage.

Reynolds F (1997) Coping with chronic illness and disability through creative needlecraft. British Joumal of Occupational Therapy, 60(8), 352-56.

Reynolds F (2002) Filling the void. Therapy Weekly, 27 June, 4. 
Reynolds F, Prior S (2003) 'A lifestyle coat-hanger': a phenomenological study of the meanings of artwork for women coping with chronic illness and disability. Disability and Rehabilitation, 25(14), 785-94.

Robinson I (1990) Personal narratives, social careers and medical courses: analysing life trajectories in autobiographies of people with multiple sclerosis. Social Science and Medicine, 30(11), 1173-86.

Silverman D (2000) Doing qualitative research: a practical handbook. London: Sage.

Smith J (1996) Beyond the divide between cognition and discourse: using interpretative phenomenological analysis in health psychology. Psychology and Health, 11(2), 261-71.

Smith J, Flowers P, Osborn M (1997) Interpretative phenomenological analysis and the psychology of health and illness. In: L Yardley, ed.
Material discourses of health and illness. London: Routledge, 68-91. Smith J, Osborn M, Jarman M (1999) Doing interpretive phenomenological analysis. In: M Murray, K Chamberlain, eds. Qualitative health psychology: theories and methook. London: Sage, 218-40.

Thompson A, Kent G, Smith J (2002) Living with vitiligo: dealing with difference. British Journal of Health Psychology, 7, 213-26.

Van Manen M (1990) Researching lived experience: human science for an action-sensitive pedagogy. New York: State University of New York.

\section{Author}

Frances Reynolds, PhD, Senior Lecturer, Department of Health and Social Care, Brunel University, Osterley Campus, Borough Road, Isleworth, Middlesex TW7 5DU. Email: Frances.Reynolds@brunel.ac.uk 